\title{
The Prediction of Drying Uniformity in Dryer Chamber System Using Computational Fluid Dynamics (CFD)
}

\author{
Daniela Chakyrova ${ }^{1, *}$, Anastas Yangyozov ${ }^{1}$, Dimitar Rusev ${ }^{1}$ and Nadezhda Doseva ${ }^{1}$ \\ ${ }^{1}$ Technical University of Varna, Dept. of Thermal Engineering, 9000 Varna, Bulgaria
}

\begin{abstract}
The Dryer Chamber System is the most commonly used one because of its simple and economical design. The present article reviews the process of drying a heat insulation material, manufactured in a flat form with various thicknesses. The flat material is arranged on pallets with a distance between each other. The disadvantage of this Dryer Chamber System is the non-uniformity in the moisture distribution in the final product due to the poor organization of the airflow in the dryer chamber. The goal of this study is to analyze the conditions for improving the uniformity of drying in the currently existing Dryer Chamber System for heat insulation materials. The factors influencing the uniformity of the humidity of the material at the outlet of the dryer are studied: the way the air moves around the material and the distribution of its speed as well as the method of its supply. The influence of the situation of the material in the drying chamber on these factors was studied. The method of computational fluid dynamics (CFD) was used to determine the velocity distribution. As a result of the numerical simulation, a scheme for organizing the space of the drying chamber has been proposed, with which to improve the distribution of the speed field. An experiment was performed to verify the results of the simulations. The performed analyzes show that the proposed scheme for improving the organization of the air movement in the drying chamber leads to the improvement of the uniformity of drying of the material.
\end{abstract}

\section{Introduction}

The Dryer Chamber System is widely used in various applications owing to its simple design and capability to dry products with a large volume. The biggest disadvantage of the dryer chamber system is the non-uniformity drying due to the poor airflow distribution in it. Various approaches can be applied for achieving uniform drying and enhancing the quality of the dried product, as reported by Misha et al. [1]. The authors use CFD analysis to predict the uniformity of drying in a chamber dryer for agricultural products during their design.

\footnotetext{
* Corresponding author: chakyrova d@,tu-varna.bg
} 
P.S.B. Zdanski et al. [2] have used numerical simulation for studying the process in a convective dryer for timber. The location of the material is studied through CFD, as well as the uniformity of the airflow around plates. The even distribution of the airflow in the drying chamber is very important since it significantly impacts the efficiency and homogeneity of the drying product. CFD is used for simulating the air pressure and it velocity profile in the dryer chamber system. The result shows that the final moisture content in the material depends on the velocity and temperature profile. The comparison between the result from the CFD simulation and the experimental data proves the essential interdependence between the drying velocity and the velocity of the air.

Computer simulations are used for evaluating the non-uniformity in temperature distribution and the moisture content in grain drying, as well as for the duration of the drying process and for the energy efficiency of various geometrical forms and control regimes [3].

A numerical study of the effect from the different widths of the free zone at the dryer inlet is presented in [4], as well as of the impact of the incoming flow in view of creating recommendations for designing, which would ensure the highest possible level of flow uniformity around the material for drying. The numerical solution of the mathematical model is obtained through Ansys CFX ver.18 and ver.19.

Chr. Lamnatou et al. [5] have elaborated and studied a numerical model for transferring heat and mass during convective drying of a porous body, using the finite-volume method. The results show that the proportions of sides of the drying plate and the flow division influence the velocity contours and the coefficients of transferring heat / mass.

Mirade [6] uses a two-dimensional (2D) CFD model with time-dependent boundary conditions to study the homogeneity of the air velocity distribution in an industrial meat dryer for several low and high levels of the ventilation cycle. All the airflow simulations show heterogeneity of drying as it is usually observed in the everyday practice.

The method of Computational Fluid Dynamics (CFD) is applied in the present research work. This method is a valuable tool for analyzing complex fluid flows related to transferring heat and mass.

On the basis of the information from the literature, it becomes clear that the question of the impact of the airflow main parameters on the uniformity of drying of various materials is relevant and requires a detailed analysis. In this relation, the present study provides an indepth discussion concerning the influence of the location of the material in the dryer chamber on the velocity and temperature fields, and, hence, on the uniformity of the moisture distribution. To analyze the conditions for improving the uniformity of drying in a existing Dryer Chamber System for heat insulation materials is the aim of this study. The distribution of the velocity of the air flow around pallets differently located within the space of the dryer with plates arranged on them is studied as well as the impact of the velocity field on drying uniformity. The method of Computational Fluid Dynamics (CFD) is used for determining the velocity distribution. An experiment has also been carried out to verify the results from the simulation study.

\section{Material and method}

\subsection{Geometry of the dryer chamber system and the material}

The studied dryer chamber has the form of a parallelepiped with dimensions $35 \mathrm{~m}$ length, $5.70 \mathrm{~m}$ width and $2.7 \mathrm{~m}$ height, and is used for heat insulation materials. The material is moulded in the form of plates (parallelepipeds) with different thicknesses, which are 
arranged on pallets. The pallets are placed with a distance between each other, so that the air can flow between them.

The main physical values, which determine the moisture distribution in the separate plates during the process of drying are temperature, velocity and air humidity. Only the impact of the drying air velocity is analyzed in this simulation study. The analysis of the air temperature and humidity is subject of another research.

The present article evaluates the influence of the following factors on the uniformity of the moisture content in the final product:

- velocity of the airflow around plates and its distribution in the chamber space, occupied by the material for drying and grouped in pallets;

- location of the pallets within the dryer space;

- distribution of the airflow at the chamber inlet by installing guiding partitions;

The following schemes are examined:

I scheme: Along the length of the chamber there are twelve blower vents supplying preheated air is delivered from the production premises, where the dryer chamber system is built. On the opposite wall of the chamber there are outlets through which the air goes out freely. There is $35 \mathrm{~cm}$ of free space above the pallets (Fig. 1, Fig. 2a without position 1).

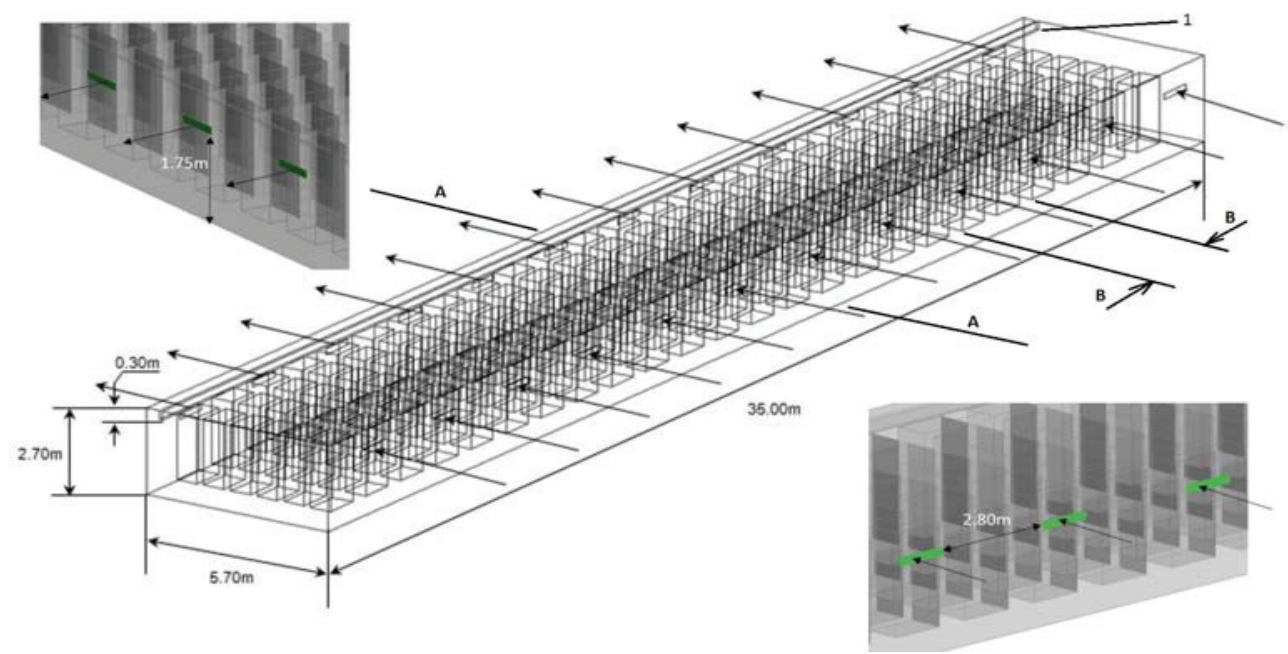

Fig. 1. General view of the dryer chamber system with the pallets, the air inlets and outlets: a) $I$ scheme: without pos.1; b) II scheme: with pos.1.

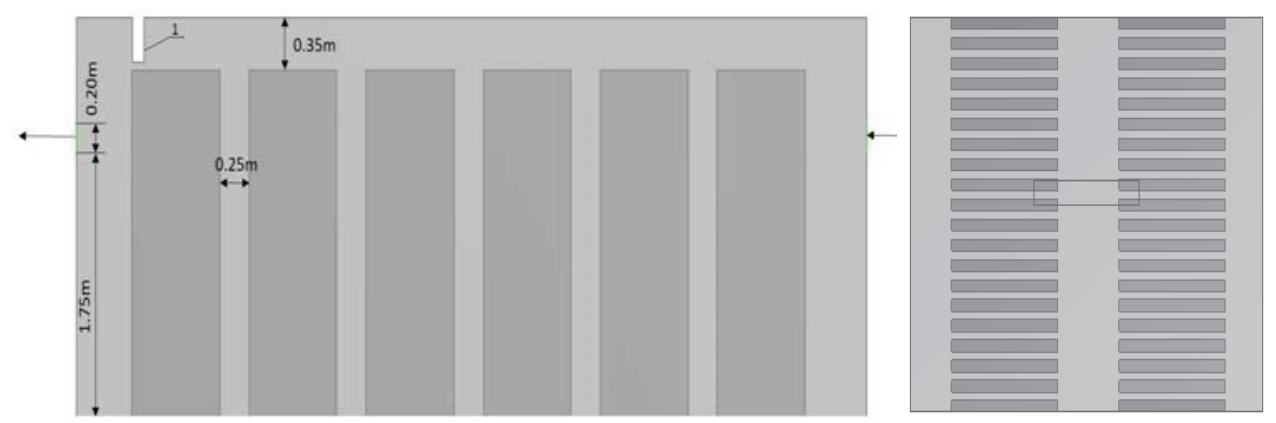

Fig. 2a. Vertical cross section (A-A) of the dryer chamber system.

Fig. 2b. Vertical cross section (b-b) of the dryer chamber system. 
II scheme: As with scheme I, however, there is a partition installed in the upper section of the dryer chamber system (above the pallets) in front of the outlets (fig. 1, pos. 1) so that the air can flow between the plates arranged in the pallets, and not to flow around them.

III scheme: It is proposed to divide the dryer chamber into four sections according to the number of the fans. Thus, there are four independent sections formed, where additional flow-guiding partitions are made in view of improving the circulation.

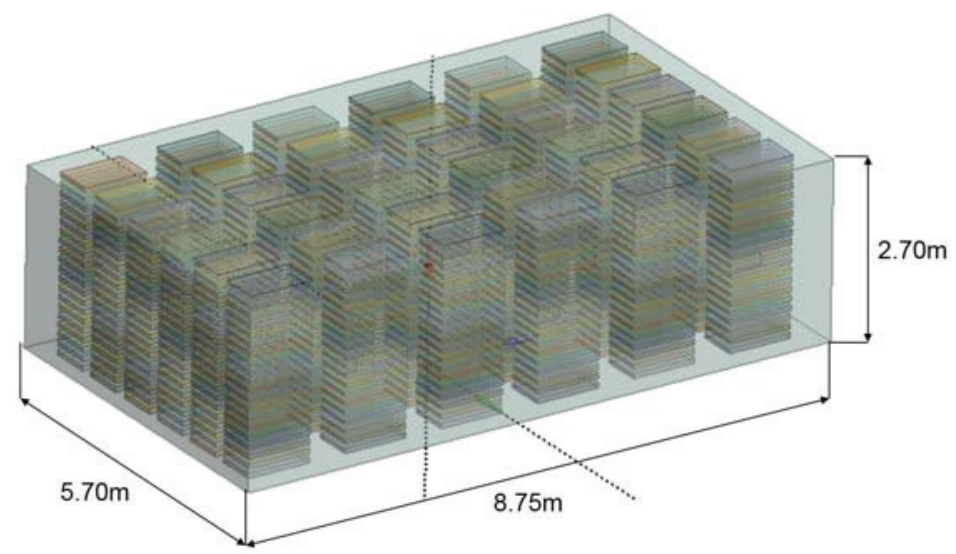

Fig. 3. III scheme: Configuration of a quarter of the dryer chamber - the space in front of 1 fan.

IV scheme: A model with a distribution grid in front of the blower vents.

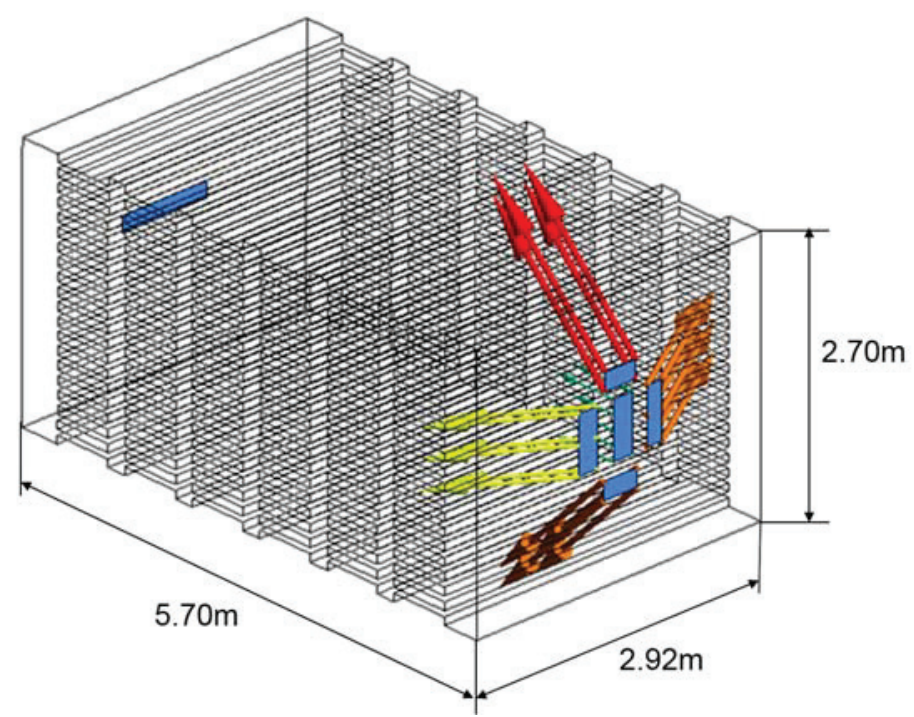

Fig. 4. IV scheme: The space in front of one ventilation opening with a distribution grille.

\subsection{Basic Governing Equations}

To the basic equations of computational fluid dynamics - the continuity, momentum and energy equations - the additional transport phenomenon of mass diffusion has not been included because we are limiting our considerations to a homogenous, unreacted chemical gas. If diffusion were to be included, there would be additional continuity equations - the species continuity equations involving mass transport of chemical species due to a 
concentration gradient in the species. Moreover, the energy equation would have an additional term to account for energy transport due to the diffusion of species. With the above restrictions in mind, the governing equations for an unsteady, three-dimensional, compressible, viscous flow are continuity equations, momentum equations (Navier-Stokes); energy equation and SST turbulence model equations $[1,2,7,8,9]$ :

The turbulent k-eps model is extremely economical in terms of computation, but experience has shown that it is not applicable to a number of problems. The reason is the artificial production of turbulent kinetic energy in the model and the distance from the real phenomena occurring in the chamber. This anomaly is the reason we do not use the k-eps turbulent model. This can be avoided by using the RNG k-eps modification. Simulations performed as LES or DNS are more accurate, but the computational resource they require is extremely large and is not applicable to the present study. The software product we use offers the ability to solve LES simulations, but the computing technology we have would be difficult to handle the many variants of this study. The SST turbulent model is the optimal option.

These transport equations in partial derivatives (PDE's) can be solved analytically for a small number of boundary and initial conditions [10]. Therefore, the CFD codes are elaborated for numerical algorithms, which can efficiently solve the PDE's, which control the fluid flow, the heat transfer and many other physical phenomena. CFD techniques can be used for building distributed parameter models, which are representative in terms of space and time for the physical system, and thus enable obtaining a solution with a high level of physical realism $[11,12]$.

\subsection{Physical properties, process parameters and boundary conditions}

The following physical properties, process parameters and boundary conditions are applied to the elaborated model:

*Air flow rate at the chamber channel inlet: $7.533 \mathrm{~kg} / \mathrm{s}$, which goes through 12 channels $(0.6278 \mathrm{~kg} / \mathrm{s}$ per channel);

*Temperature under static parameters at the chamber inlet: $40{ }^{\circ} \mathrm{C}$;

*Pressure at the drying chamber outlet: $0 \mathrm{~Pa}$ (gauge pressure);

*Registering the convective effects in the fluid area:

- on axis X: $0 \mathrm{~m} / \mathrm{s}^{2}$;

- on axis $\mathrm{Y}: 0 \mathrm{~m} / \mathrm{s}^{2}$;

- on axis $\mathrm{Z}$ : - $9,81 \mathrm{~m} / \mathrm{s}^{2}$;

* Air density $-1.13 \mathrm{~kg} / \mathrm{m}^{3}$;

* The examined area is stationary;

* Turbulence model: Shear-Stress Transport SST k- $\omega$;

* The model takes into account the viscous dissipation.

An industrial dryer is modeled, as the boundary conditions are set by the measuring instruments in the technological system.

\subsection{Simulation Details}

The discretization of the fluid area is carried out by generating elements of the type Tetrahedra, Pyramids and Hexahedra. The number of the elements varies in the studied models from 168726 to 3908340 (3.9 million). The two types of grids are generated with the variants - structured and unstructured. The results are unambiguous and close, however, there is a difference in the time for calculation. It takes the shortest time to calculate a model with a structured grid. The time for calculation of the task with 3.5 million finite elements is $4 \mathrm{~h} 50 \mathrm{~min}$. When using the structured grid for $1 / 4$ of the dryer chamber system 
and calculating with a two-processor workstation, the calculation time is $10 \mathrm{~min}$. The numerical scheme for calculation has the following settings of the Advection Scheme solver: High Resolution, Fluid Timescale Control: Auto timescale.

The number of elements depends on the model being calculated. In the present study, simulations were made with the whole facility and simulations with part of it. When developing the models, the size and number of elements near the walls of the slabs and the chamber of the facility are monitored. We check for $y+$ according to the recommendations given by ANSYS Meshing and we comply with the capabilities of the computing equipment we have.

\section{Results and discussion}

\subsection{Simulation study - CFD analysis of the various schemes of positioning the material in the dryer chamber}

\subsubsection{Impact of the dryer chamber space organization on the uniformity of material drying}

\section{I scheme:}

The air moves along channels with the least resistance, and, therefore, there are spaces left where there is no air movement such as the space above the pallets, for example. Drying is slower on those stagnant areas compared to the areas with intensive air movement. This can be seen with the simulations on fig.6 and 7. The simulations are made by schemes I and II according to fig. 1 and fig. 2.

Fig. 5 presents fluid domain mesh model with 2848782 elements and with 565344 nodes for chamber of schemes I according to fig. 1.

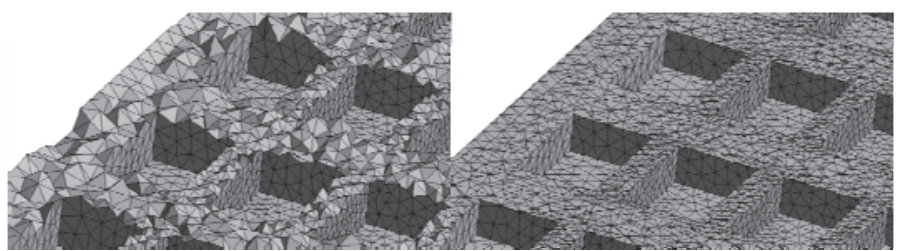

Fig. 5. Fluid domain mesh model with 2848782 elements and with 565344 nodes for chamber of schemes I according to fig. 1.

It can be seen on fig. 6 and 7 that when the air is moving from the inlet to the outlet, its velocity decreases up to three times. That means that at the chamber inlet there is a more intensive drying process going on than in the outlet areas, where velocity and temperature have lower values.

As result, it can be concluded that the material around the chamber inlet areas will have lower moisture content than the material positioned around the outlet areas.

\section{II scheme:}

Fig. 8 represents fluid domain mesh model (b) with 3908340 elements and with 768764 nodes for chamber of schemes II according to fig. $2 b$.

The results from the CFD simulation are presented on fig. 9, 10

The installation of the partition lengthens the path of the air in the chamber, and, thus, there are more areas that are flown around by it. It becomes evident from the velocity contours on fig. 9 and 10. The applied measure improves the flowing around of the material, placed in the dryer chamber system, however, it is not enough to achieve 
uniformity. There are still areas remaining where the flowing around of the plates in the pallets is done at low velocity.

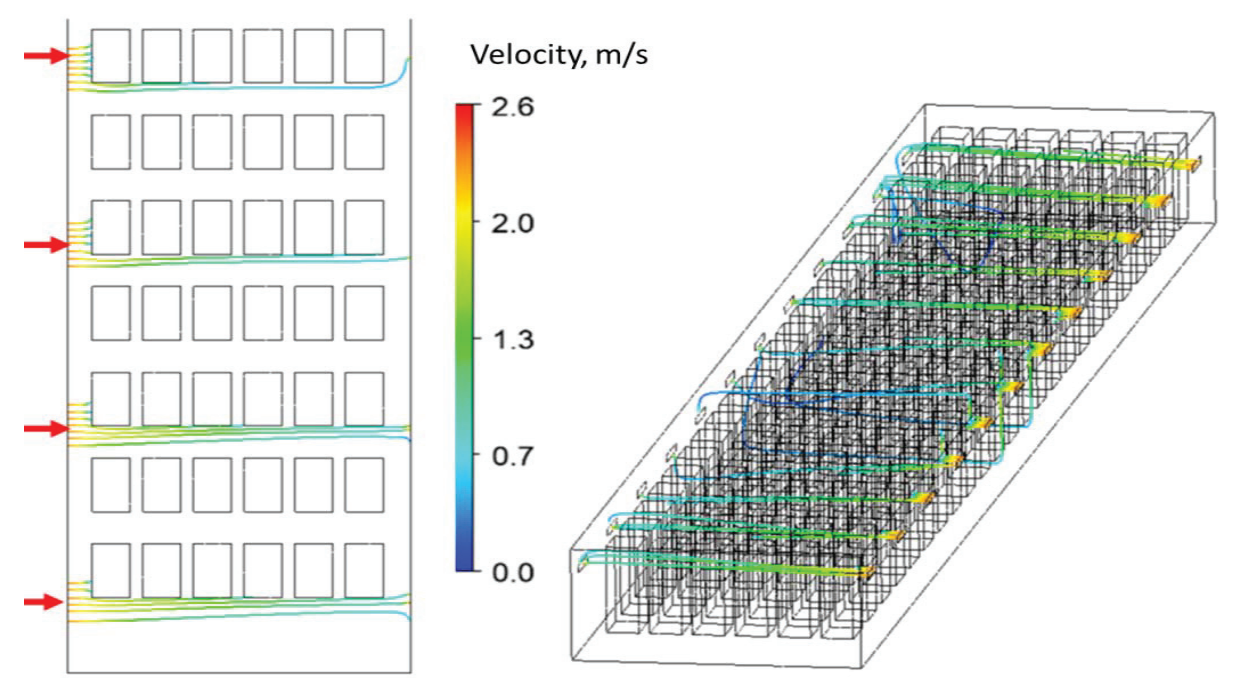

Fig. 6. Plan of the dryer chamber system

Fig. 7. 3D General view.

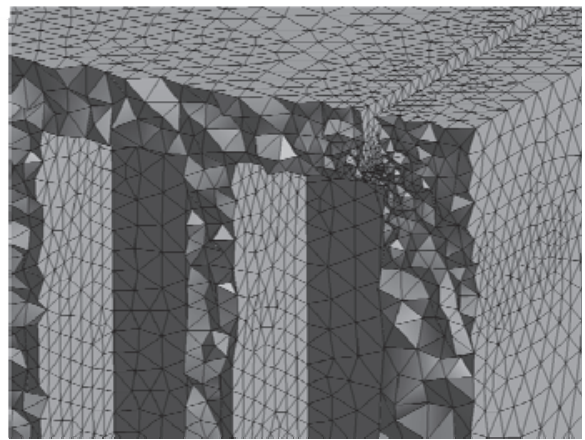

Fig. 8. Fluid domain mesh model (b) with 3908340 elements and with 768764 nodes for chamber of schemes II according to fig. $2 \mathrm{~b}$.

The analysis of the obtained results shows that it is necessary to apply additional measures to improve the air circulation in the chamber. The following scheme is proposed.

\subsubsection{Impact of material positioning on air flow in the dryer chamber}

\section{III scheme:}

For the scheme presents of fig. 3 are made numerical calculations done in 2 main variants. Scheme I is realized with the first one - there is no pos.1 (fig. 1). With the second variant there are pos. 1.

There are calculations made for each of the main variants with different positioning of the pallets in the examined space (scheme I and scheme II). 


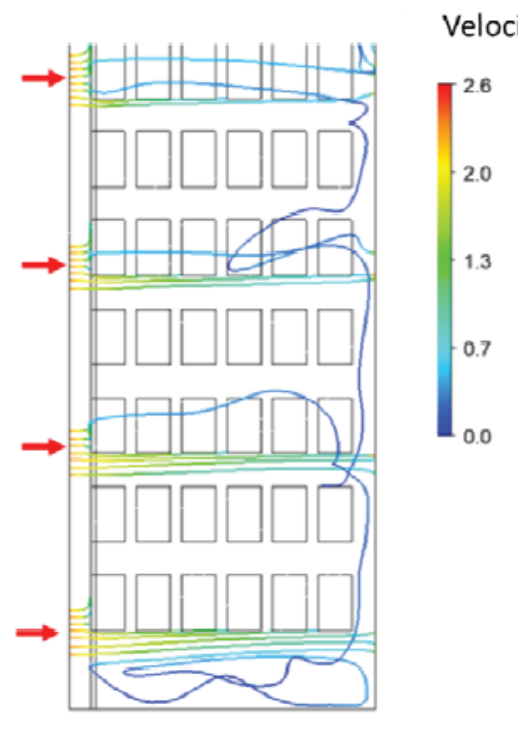

Fig. 9. Plan of the dryer chamber system.

\section{Velocity, $\mathrm{m} / \mathrm{s}$}

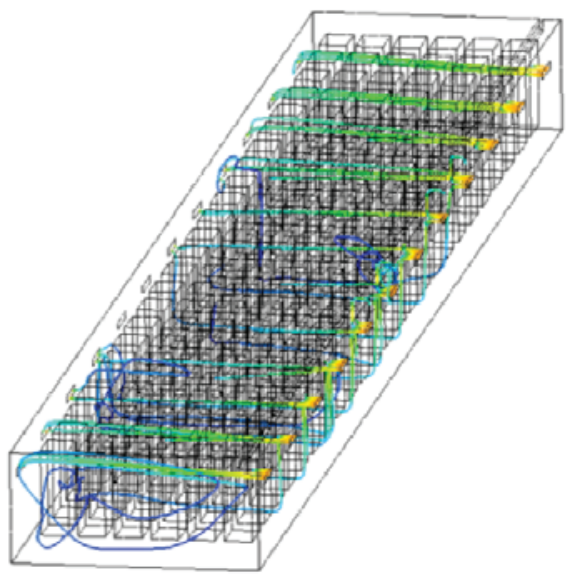

Fig. 10. 3D model of the chamber with streamlines.

The figures from 11 to 14 show the velocity contours in a horizontal plane (fig. 15a) for those schemes, where the positioning of the pallets in the chamber and the size of the distance between them are examined.

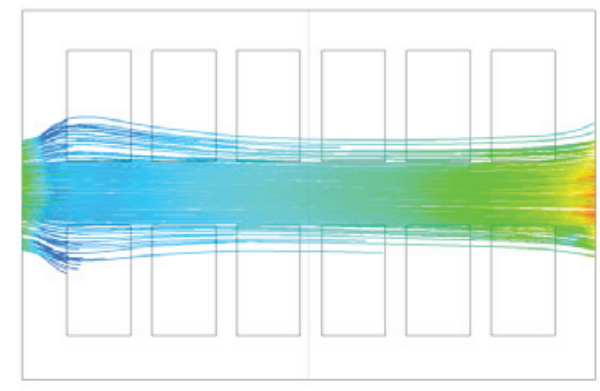

Fig. 11. Model 1: Velocity contours for corridor arrangement of the pallets with 0,25 $\mathrm{m}$ distance in the row and $0,72 \mathrm{~m}$ between the rows.

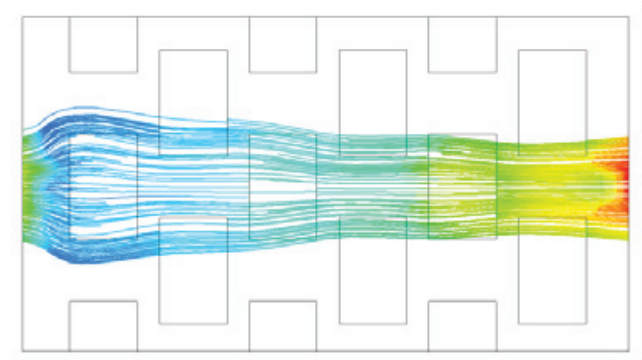

Fig. 13. Model 3: Velocity contours with staggered arrangement of the pallets with $0,25 \mathrm{~m}$ distance in the row and $0,72 \mathrm{~m}$ between the rows.

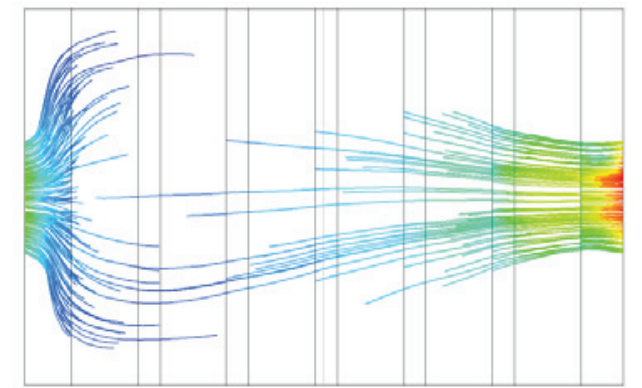

Fig.12 Model 2: Velocity contours for tightly arrangement of the pallets with $0,25 \mathrm{~m}$ distance in the row and $0,0 \mathrm{~m}$ between the rows.

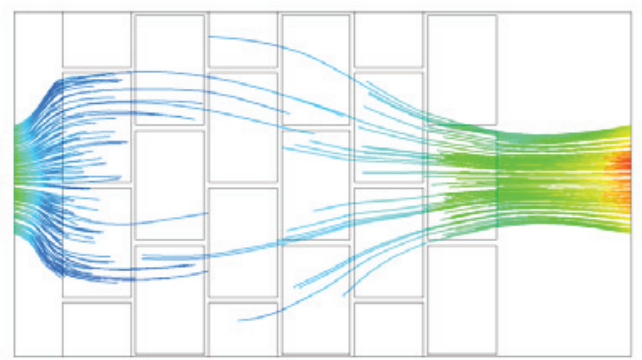

Fig. 14. Model 4: Velocity contours for staggered tightly arrangement of the pallet rows both in the rows and between them. 
The distribution of the air flow velocity lines was studied under the following conditions: 1) corridor arrangement of the pallets with $0,25 \mathrm{~m}$ distance in the row and 0,72 $\mathrm{m}$ between the rows and tightly arrangement of the pallets with $0,25 \mathrm{~m}$ distance in the row and $0,0 \mathrm{~m}$ between the rows (Figs. 11 and 12);2) staggered arrangement of the pallets with $0,25 \mathrm{~m}$ distance in the row and $0,72 \mathrm{~m}$ between the rows and tightly arrangement of the pallet rows both in the rows and between them (Figs. 13 and 14).

There are the same borderline conditions maintained for all the variants, however, recalculation is made for some of the variants with width less than $4 \mathrm{~m}$.

The geometric conditions of the simulation are presented in a table 1.

Table 1. Geometric conditions for simulation

\begin{tabular}{|c|c|c|c|}
\hline $\begin{array}{c}\text { № of } \\
\text { model }\end{array}$ & Arrangement of pallets & $\begin{array}{c}\text { Length of free space } \\
\text { transverse to the flow, } \mathrm{m}\end{array}$ & $\begin{array}{c}\text { Filling ratio of the } \\
\text { drying chamber }\end{array}$ \\
\hline 1 & Corridor & 1,9 & 0,4 \\
\hline 2 & Dense & 0 & 0,667 \\
\hline 3 & Staggered & 1,9 & 0,421 \\
\hline 4 & Staggered & 1,26 & 0,635 \\
\hline
\end{tabular}

From Figures 11 to 15 it can be seen that when the coefficient of filling the space of the drying chamber (Table 1) is higher, the air flows around all pallets with close velocity and thus ensures even drying of material (the contours of the velocity field are distributed more equally). This is due to the fact that the free space between the rows is reduced, which makes the resistance of the channels through which the air passes with close values. The vortices are especially visible in the corridors between the rows of pallets in fig. 15 and 16 . This is observed both in the corridor arrangement and in the staggered arrangement.

The next figures present the picture of the velocity contours in vertical and horizontal planes of the part of the dryer chamber, which is presented on fig. 3 .

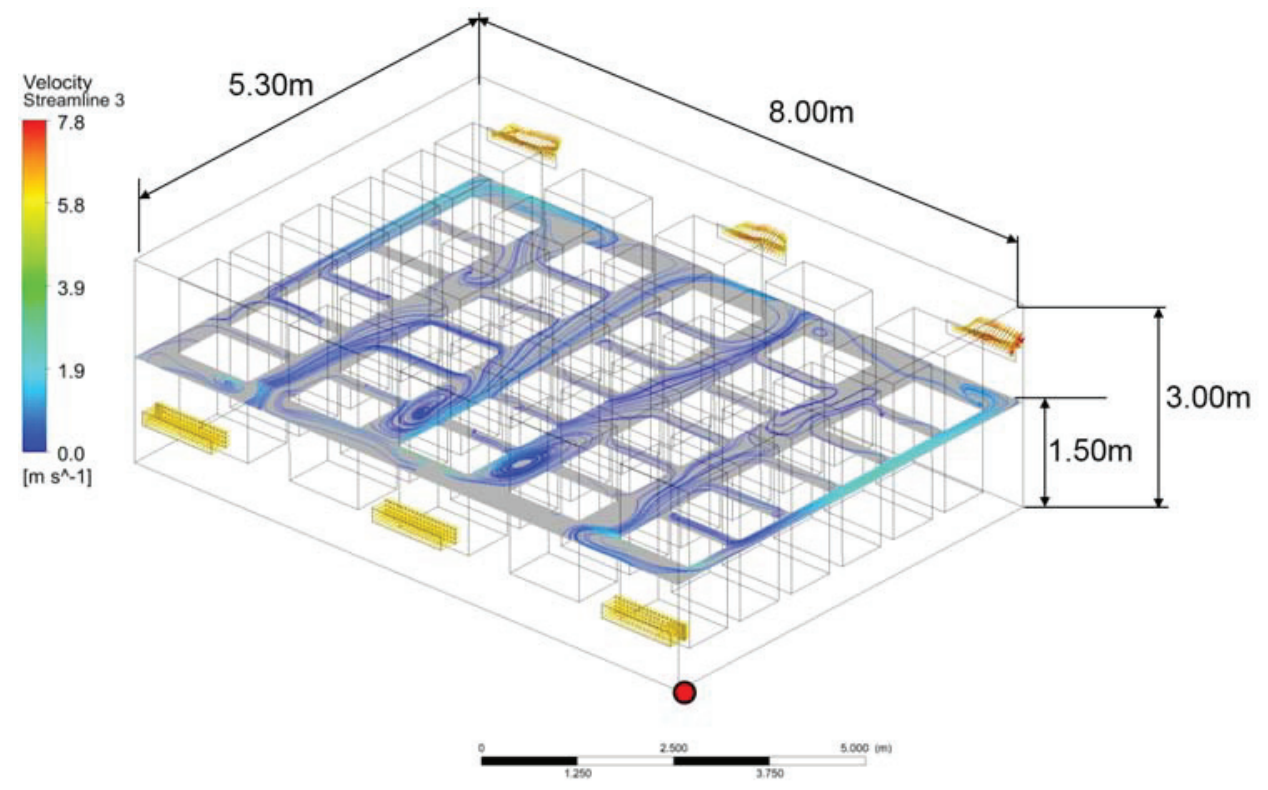

Note: The red circle is the center of the coordinate system.

(a) 


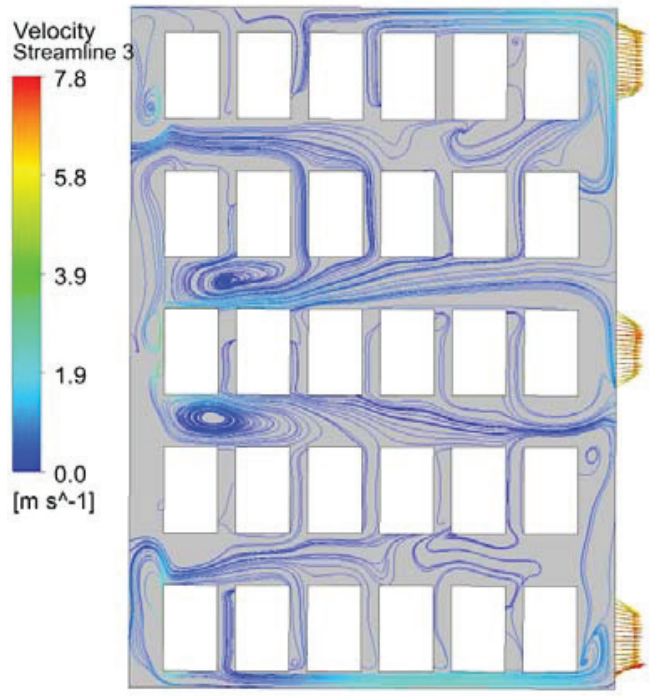

(b)

Fig. 15. A position of a horizontal plane in the dryer chamber (a) and velocity contours (b) in this plane.

It is evident from the picture of the velocity contours on fig. $17 \mathrm{~b}$ that in the area around the air outlets there are stagnant areas with vortices due to the low values of the velocity of flowing out through the openings. Flowing around can be improved if suction ventilation is provided (in combination with a grid and a distance between the in-blowing gratings and the palets).

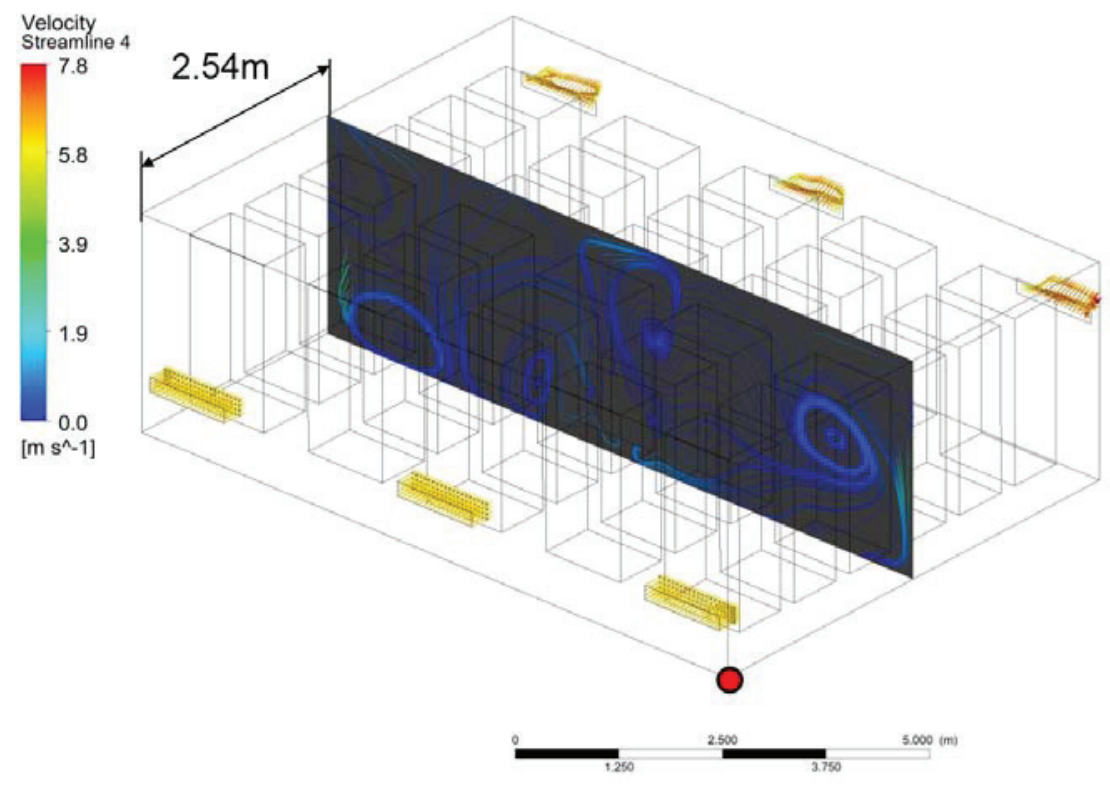

Note: The red circle is the center of the coordinate system.

(a) 


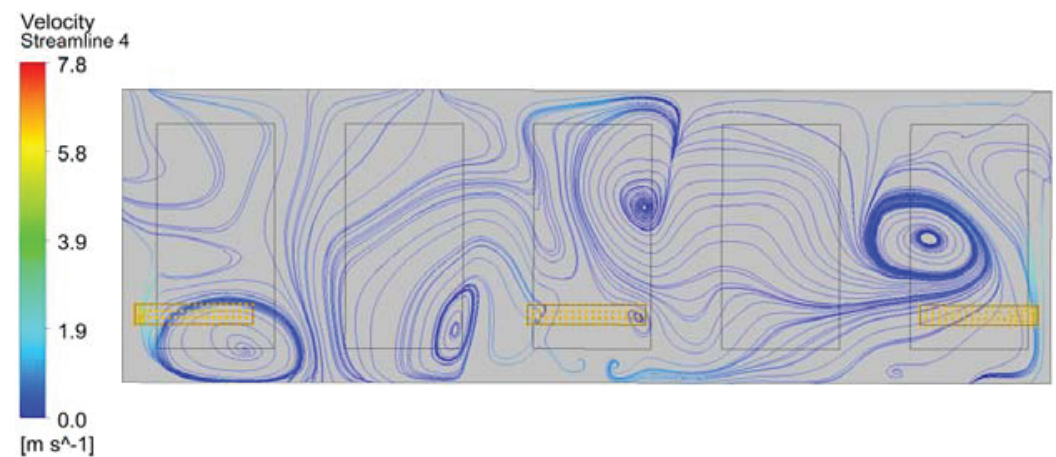

(b)

Fig. 16. A position of a vertical plane in the dryer chamber (a) and velocity contours (b) in this plane.

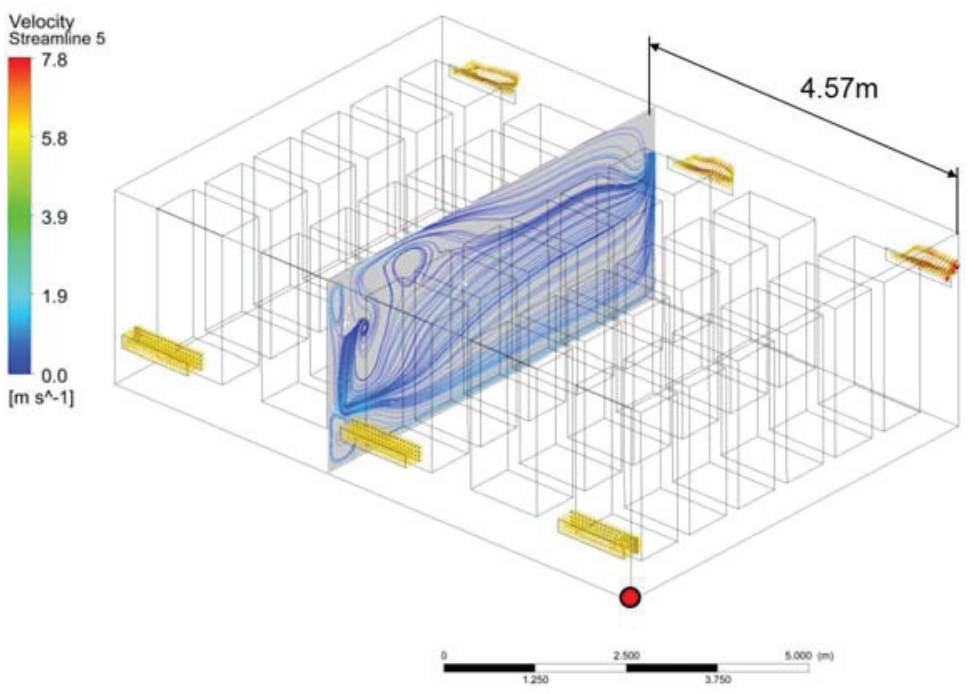

Note: The red circle is the center of the coordinate system.

(a)

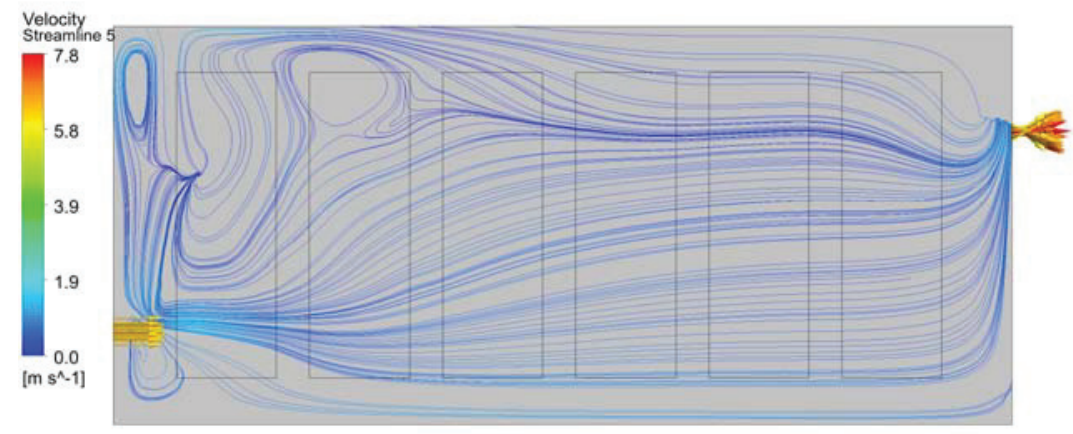

(b)

Fig. 17. A position of a vertical plane in the dryer chamber (a) and velocity contours (b) in this plane. 


\subsubsection{Impact of the method of air supply and its distribution on the uniformity of material drying}

\section{IV scheme:}

The simulation studies of the previous three schemes have led to the conclusion that there should be guiding grid installed to the openings for the incoming air, which would provide uniform air distribution in the horizontal and vertical planes. In this respect, there is a model examined (fig.4), where such grid is installed in front of the blower vents. Fig. 18 show the velocity vectors, using the positioning of the pallets from Model 2 (fig. 12). The results from the calculations are presented on fig. 19 and 20.

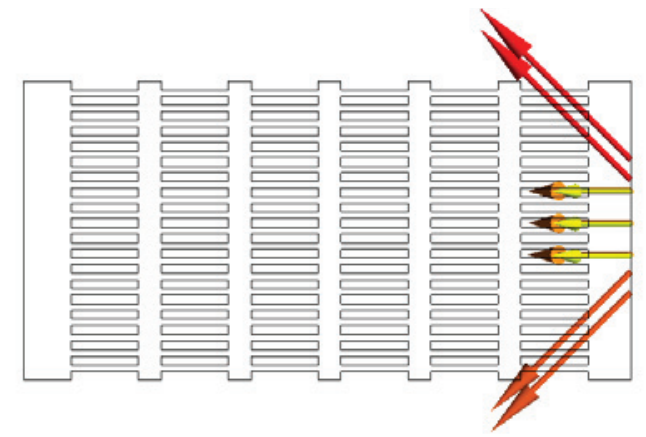

Fig. 18. Plan of the dryer chamber system.

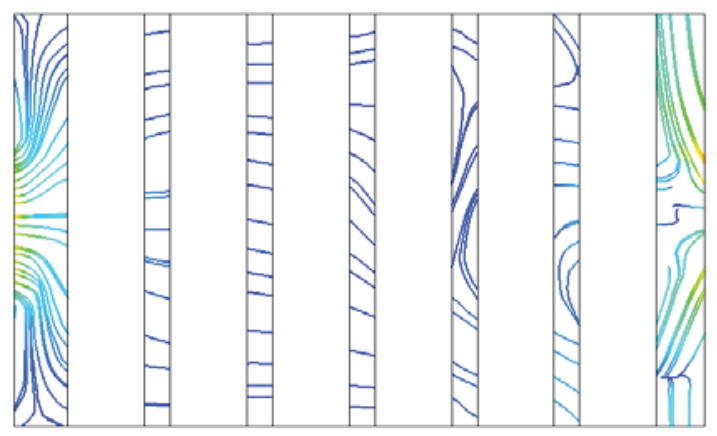

Fig. 19. Velocity contours in the horizontal plane (a-a)

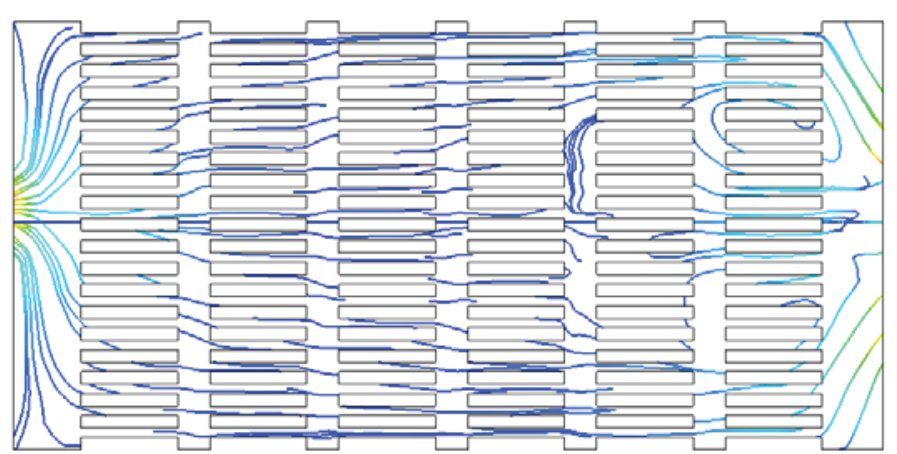

Fig. 20. Velocity contours showing the air distribution in the vertical plane (vertical section of the chamber b-b) 
Evidently, the installation of guiding grid improves the air distribution in the dryer chamber space.

\subsection{Verification of the simulation results}

According to the proposed measures, a test chamber according to Scheme 3 was developed in this study in the existing drying chamber. Two pallets are considered - one with a horizontal arrangement of the plates material fig. 21a, and the other with vertical fig. $21 \mathrm{~b}$.

The both pallets are positioned next to the door of the test chamber. An experiment is conducted, where mass is measured of the separate plates. Measuring is done before the start of drying and after its completion. Analyzed are two same pallets with a horizontal arrangement of the plates material, one of them placed in the test chamber with the new space organization (scheme III), and the other - under the current conditions (scheme I). The results are shown on fig. $22 \mathrm{a}$ and $22 \mathrm{~b}$.

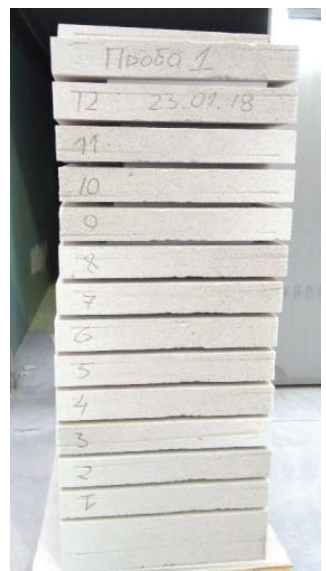

(a)

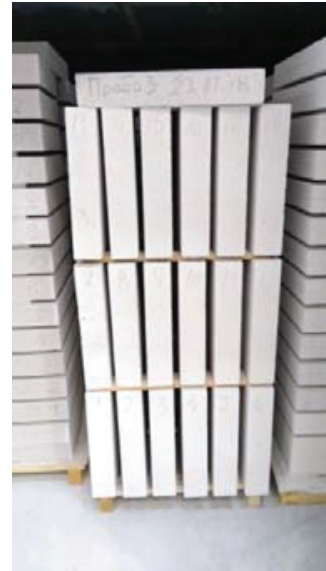

(b)

Fig. 21. Test pallets with heat insulation material: horizontally arranged plates (a); vertically arranged plates (b).
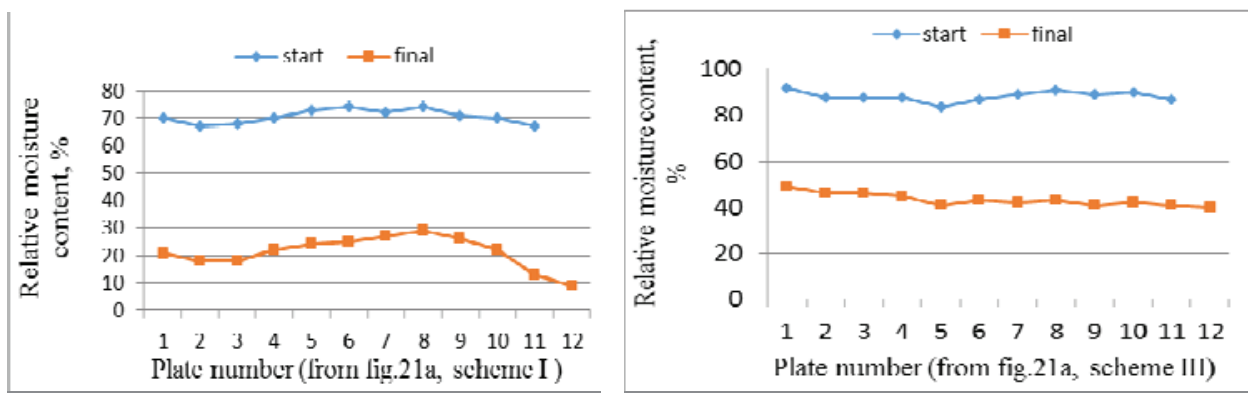

Fig. 22. Relative moisture content (test pallet fig.21a), \%: (a) scheme I (fig. 1); (b) scheme III (fig. 3).

The comparison of the results from the measuring of the relative moisture content of the insulation materials (before the change of the chamber space organization, fig. 21a) with the results from the simulation calculations (fig. 16 and 17) shows that as a result from the better flowing around of the plates at the upper side of the pallet, the plates with number 11 and 12 are the driest, while the plates with numbers 7,8 and 9, positioned in the medium area of the pallet where flowing around is the weakest, have the highest moisture. After changing the drying area organization and improving the air circulation, there is substantial 
improvement established in the uniformity of drying (fig. 22b). The plates with numbers from 5 to 12 have very similar relative moisture content, while the relative moisture content of the plates at the lower side of the pallet with numbers from 1 to 4 deviates by 15 to $22 \%$.

An experiment has also been conducted with vertical positioning of the plates in the pallet with the channels between them oriented in the direction of the air movement (fig. $21 \mathrm{~b})$. The results from the measurements of the relative moisture content are shown on fig. 23.

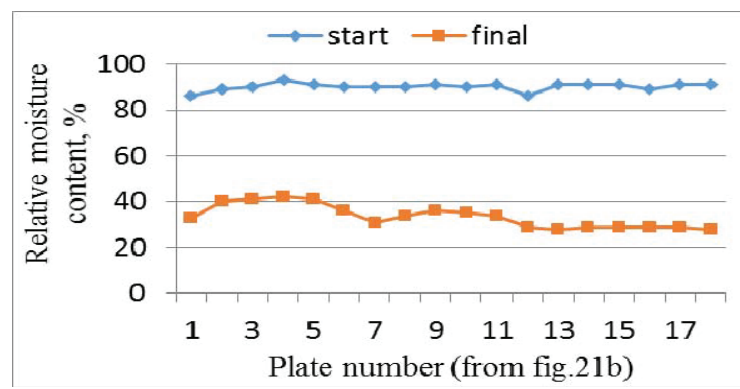

Fig. 23. Relative moisture content (vertically arranged plates).

\section{Conclusions}

In an industrial drying chamber for insulating material, the manufacturer observes a nonuniformity distribution of the moisture content in the outlet product. At the request of the manufacturer, a study of the process was made by CFD simulation and the following reasons were identified: 1) the air movement channels, formed by the way the material is arranged, have different resistance, which helps the formation of stagnant zones. In them the air moves at low speeds and the drying intensity is low; 2) the rectangular opening through which the air is injected does not create conditions for its uniform distribution in the volume of the chamber; 3 ) the total volume of the drying chamber is serviced by four fans with three discharge openings, which makes it difficult to organize the air in it.

The measures for improving the uniformity of drying of the material, proposed as a result of the conclusions from the simulations, are:

1. Reduction of the free volume above the pallets;

2. Reduction the step between the pallets in the horizontal plane;

3. Placement of a distribution grille at the air inlet, which ensure uniform distribution of air in the horizontal and vertical planes.

A test chamber was built by the manufacturer as part of the existing one and experimental tests were carried out to verify the results of the simulation study.

The results of the experiment show that:

1. The proposed form of organization of air exchange in the space of the dryer leads to the improvement of the uniformity of drying of the insulating material.

2. The humidity of the material is still higher at the bottom of the pallets. The results are expected to improve with the application of a distribution grille at the air inlets in the drying chamber.

3. The vertical arrangement of the material plates on the pallets leads to a shortening of the drying time. 
The authors would like to express their gratitude to Eng. Yordan Ovcharov for the provided assistance in verifying the results from the simulations.

\section{References}

1. S. Misha, S. Mat, M. H. Ruslan, K. Sopian, and E. Salleh, Int. J. of Machine Learning and Comp., 3, 5 (2013)

2. P.S.B. Zdanski , D.G. Possamai , and M. Vaz Jr., J. of App. Fluid Mechanics, 8, 3, 367-376 (2015)

3. O.A. Khatchatouriana, H.A. Vielmo, L.A. Bortolaia, 116, 335 - 345 (2013)

4. M. Song, K. Kim, H.-K. Yoon, New \& Renewable Energy, 12, 3 (2016)

5. C.Lamnatou, E.Papanicolaou, V.Belessiotis, N.Kyriakis, Renewable Energy, 35, 7, 1391-1402 (2010)

6. P.-S. Mirade, J. of Food Eng., 60(1), 41-48, (2003), DOI: 10.1016/S02608774(03)00009-8

7. ANSYS CFX-Solver Theory Guide, Release 14.0, (November 2011)

8. F. Menter, Turbulenzmodellierung für Aerodynamische Anwendungen. Aerodynamik und Turbulenzmodellierung. Turbulenzmodelle in der Praxis, (2003)

9. P. Durbin, Engineering Turbulence Modeling and Experiments 5: A Perspective on Recent Developments in RANS Modeling. Elsevier Science, (2002)

10. O. Yongsona, I. A. Badruddina, Z.A. Zainala, P.A. Aswatha Narayana, Building and Environment 42, 1531-1537 (2007)

11. T. Norton, B. Tiwari, and Da-Wen Sun, Critical Reviews in Food Science and Nutrition, 53, 251-275 (2013), Copyright Taylor and Francis Group, LLC, ISSN: 1040-8398 / 1549-7852 online

12. S.Rajasekar, N.Meyyappan, D.G.Rao, JOFSR, 1(1), 027-031, (2016). 